\title{
ETIOLOGIA SÂNGERĂRILOR GASTROINTESTINALE LA COPIL
}

\author{
Nicoleta Gimiga, Smaranda Diaconescu, Claudia Olaru, Alexandru Olaru, \\ Gabriela Păduraru, Ancuța Ignat, Marin Burlea \\ Universitatea de Medicină şi Farmacie ,, Gr. T. Popa “, Iaşi
}

\begin{abstract}
REZUMAT
Obiective. Identificarea caracterelor clinice, endoscopice, etiologice la copiii diagnosticați cu hemoragie digestivă superioară şi inferioară.

Material şi metodă. S-a efectuat un studiu retrospectiv descriptiv pe o perioadă de 3 ani (ianuarie 2010decembrie 2012) pe 107 copiii cu vârsta între 1 şi 18 ani, internați pentru hemoragii digestive în Spitalului Clinic de Copii „Sf. Maria“ laşi. Lotul de studiu nu cuprinde hemoragii digestive din urgențe chirurgicale, boli infecțioase, boli intestinale cu mecanism imunologic sau toxic. Analiza retrospectivă individualizată prin studiul foii de observație a cuprins date anamnestice, clinice, endoscopice şi histologice orientate pentru diagnosticul etiologic al hemoragiilor digestive. Toți pacienții au fost investigați prin endoscopie digestivă superioară/colonoscopie după ce procedura a fost explicată şi s-a obținut consimțământul informat.

Rezultate. Din lotul de 107 copii luați în studiu $39(36,4 \%)$ au reprezentat hemoragia digestivă superioară (HDS), dintre care 6 cazuri (5,1\% ) de cauza variceală iar 33 (94,8\%) de cauză non variceală; şi 68 (63,5\%) au prezentat hemoragia digestivă inferioară (HDI). În etiologia HDS gastrita erozivă a reprezentat $12(30,8 \%)$ cazuri, esofagita $6(15,4 \%)$, duodenita $6(15,4 \%)$, ulcerul duodenal $4(10,3 \%)$, ulcerul gastric $2(5,1 \%)$, sindrom Mallory Weiss 1 (2,6\%), etiologie multiplă $6(15,4 \%)$ cazuri. Principalele aspecte etiologice ale HDI au fost polipul colo-rectal în $28(41,2 \%)$ cazuri, colită ulcerativă $14(20,6 \%)$, leziuni nespecifice $12(17,6 \%)$ fisuri anale $9(13,4 \%)$, sindroame de polipoză intestinală $3(4,4 \%)$, malformație vasculară $1(1,5 \%)$, diverticul rectal $1(1,5 \%)$ caz. S-au practicat intervenții endoscopice concomitente în cazul polipilor colo-rectali.

Concluzii. Hemoragia digestivă inferioară a fost cea mai frecventă, corelată cu cauze minore: polipi colorectali, fisuri anale, leziuni nespecifice.

Hemoragia digestivă non-variceală forma cea mai frecventă s-a asociat cu gastrita erozivă, esofagita, duodenita, ulcerul gastric.

Endoscopia digestivă s-a dovedit a fi o investigație utilă în diagnosticul hemoragiilor digestive şi cu aport terapeutic în anumite cazuri.
\end{abstract}

Cuvinte cheie: copil, sângerare gastrointestinală, etiologie, endoscopie, colonoscopie

\section{INTRODUCERE}

Hemoragia digestivă rămâne una dintre cele mai mari, frecvente şi importante urgențe ale gastroenterologiei pediatrice, din punct de vedere diagnostic, dar şi sub aspect terapeutic.

Incidența hemoragiilor digestive nu este foarte bine stabilită, în Europa hemoragia digestivă superioară (HDS) reprezintă $0,4-1,6 \%$ (1), în timp ce hemoragia digestivă inferioară (HDI) totalizează $0,3 \%$ dintre prezentările în urgență. (2)

În practica pediatrică sunt descrise variate aspecte etiologice ale hemoragiilor digestive de la aspecte benigne care nu necesită niciun tratament pană la etiologii cu potențial sever care necesită intervenție imediată.

\section{OBIECTIVE}

Identificarea caracterelor clinice, endoscopice şi etiologice la copii diagnosticați cu hemoragie digestivă superioară şi inferioară

\section{MATERIAL ŞI METODĂ}

S-a efectuat un studiu retrospectiv descriptiv pe o perioadă de 3 ani (ianuarie 2010-decembrie 2012) 
pe 107 copiii cu vârsta între 1 şi 18 ani, internați pentru hemoragii digestive în Spitalului Clinic de Copii „Sf. Maria“ Iaşi, care s-au adresat în perioada sus menționată pentru: hematemeză, melenă, rectoragie, hematochezie, sau cel puțin două teste consecutive pentru hemoragii oculte pozitive. Lotul de studiu nu cuprinde hemoragii digestive din urgențe chirurgicale, boli infecțioase, boli intestinale cu mecanism imunologic sau toxic, pacienții care au ingerat substanțe care pot fi confundate cu falsă hemoragie (fructe şi legume care conțin peroxidază: broccoli, ridichi, roşii, supă de sfeclă, afine, băuturi care conțin colorant roşu, suplimente de fier, săruri de bismut). (3)

Analiza retrospectivă individualizată prin studiul foii de observație a cuprins date anamnestice, clinice, endoscopice şi histologice orientate pentru diagnosticul etiologic al hemoragiilor digestive. Toți pacienții au fost investigați prin endoscopie digestivă superioară/colonoscopie după ce procedura a fost explicată şi s-a obținut consimțământul informat.

Pacienții au fost sub anestezie generală cu propofol sau sedare cu midazolam în funcție de vârstă.

Lotul de pacienți a fost împărțit în două subloturi, în funcție de localizarea sângerării, unul cu hemoragie digestivă superioară cuprinzând 39 de pacienți şi unul cu hemoragie digestivă inferioară, totalizând 68 de pacienți.

$\mathrm{Au}$ fost realizate biopsii sub directa vizualizare a mucoasei iar pentru detecția $H$. pylori s-au folosit specimene de mucoasă: testul rapid al ureazei, examinare microscopicăşi culturi din materialul bioptic.

În cadrul studiului efectuat, analiza statistică şi reprezentările grafice au fost realizate cu ajutorul programului SPSS 20.

\section{REZULTATE}

Am inclus în studiu 107 pacienți cu hemoragie digestivă superioară şi inferioară documentată care s-au adresat clinicii noastre în perioada studiată.

\section{Sublotul cu hemoragie digestivă superioară (HDS)}

Sublotul cazurilor de HDS a cuprins 39 de pacienți, cu vârste între 1 şi 18 ani, vârsta medie fiind de $9,56 \pm 5,38$ ani. $22(56,4 \%)$ au fost băieți, iar 17 $(43,6 \%)$ au fost fete. Motivele principale de internare a fost hematemeza $18(46,2 \%)$, melena 14 $(35,9 \%), 7$ pacienţi $(17,9 \%)$ s-au prezentat cu ambele simptome, atât hematemeză, cât şi melenă. (Fig. 1)

Consumul de medicamente a fost implicat în cazul a 8 pacienți $(20,5 \%)$, hemoragia asociindu-se cu gastrită erozivă, ulcer gastric, esofagită. (Fig. 2)

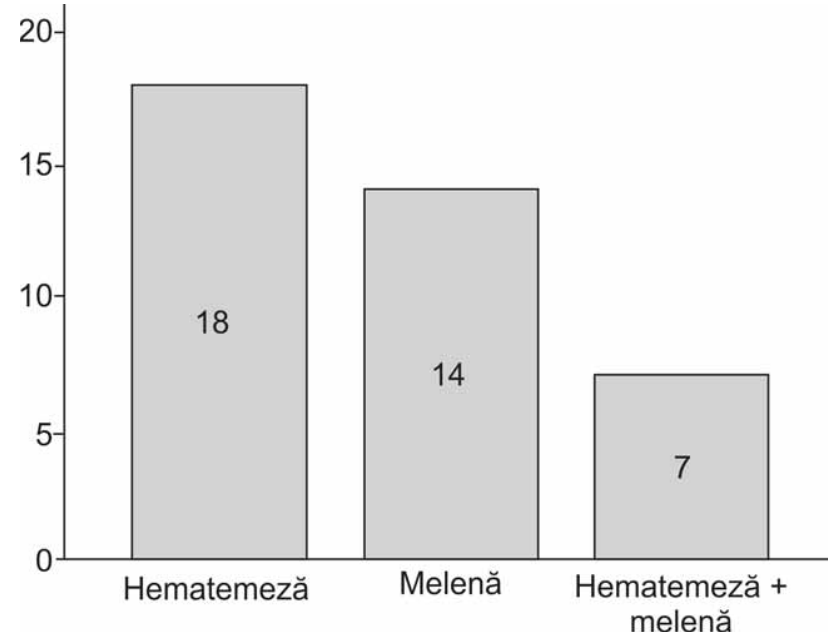

FIGURA 1. Motivele prezentării în sublotul cu hemoragie digestivă superioară

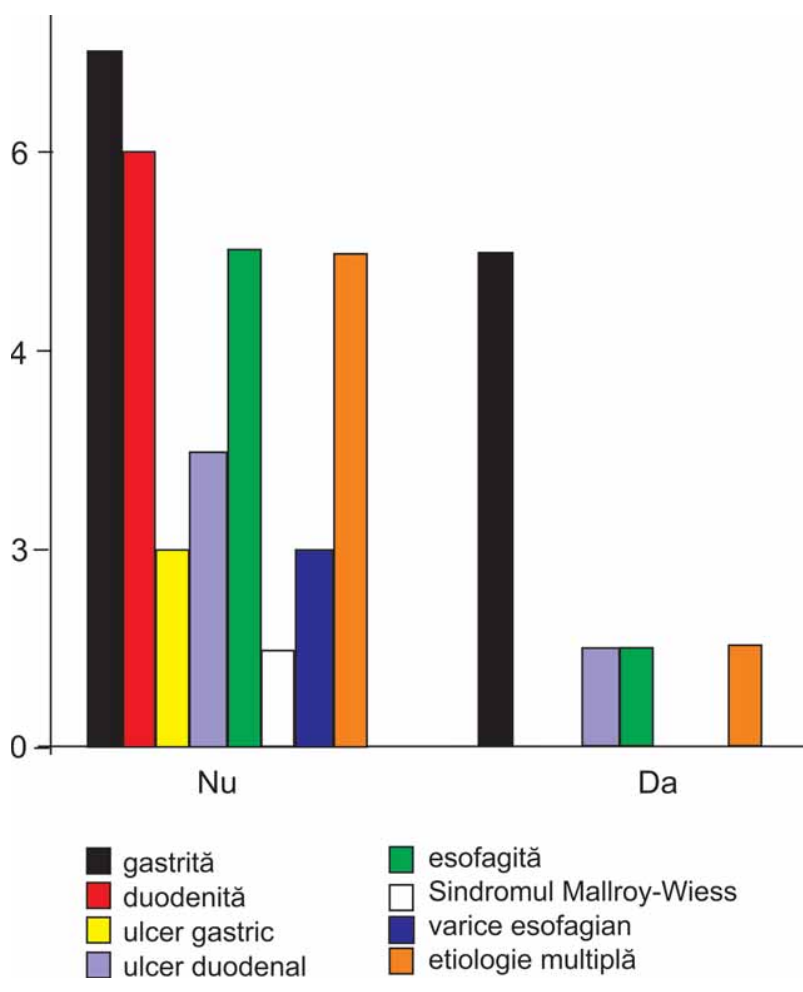

FIGURA 2. Consumul de antiinflamatorii nesteroidiene pe sublotul cu hemoragie digestivă superioară

Mai mult de jumătate $(51,3 \%)$ din lotul cu HDS au prezentat infecție gastrică cu $H$. pylori. La aceşti pacienți au predominat duodenitele şi ulcerul duodenal. (Fig.3)

Cea mai frecventă cauză a HDS constatată în sublotul studiat este gastrita erozivă, $12(30,8 \%)$. urmată de esofagită $6(15,4 \%)$, duodenită $6(15,4 \%)$, ulcerul duodenal $4(10,3 \%)$, ulcerul gastric 2 $(5,1 \%)$, varicele esofagiene $2(5,1 \%)$, sindromul Mallory-Weiss $1(2,6 \%)$, etiologie multiplă $6(15,4 \%)$ (gastrită şi duodenită, esofagită şi gastrită, gastrită 


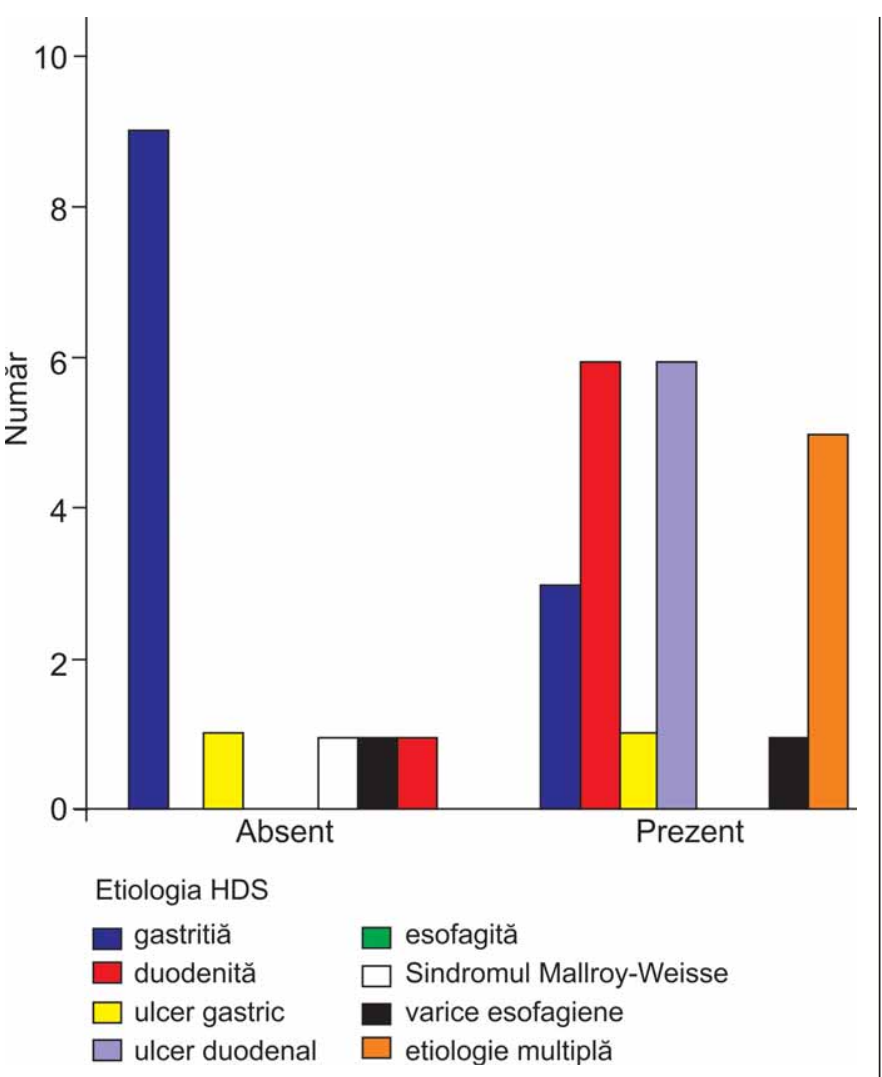

FIGURA 3. Prezența H. pylori corelat cu etiologia pe sublotul cu hemoragie digestivă superioară

şi ulcer duodenal, esofagită şi ulcer gastric, gastrită şi polip gastric, ulcer gastric şi duodenal). (Fig.4)
Departajarea cazurilor pe sexe a evidențiat că principala cauză a fost gastrita erozivă $(27,3 \%$ pentru băieți şi $23,5 \%$ pentru fete), urmată de etiologii ca esofagita şi duodenita (cu câte $22,7 \%$ fiecare) pentru sexul masculin şi ulcerul duodenal şi duodenita $(17,6 \%$ şi respectiv $5,9 \%)$ pentru sexul feminin.

\section{Sublotul cu hemoragie digestivă inferioară (HDI)}

Sublotul cazurilor de HDI a cuprins 68 de pacienți, cu vârsta cuprinsă între 1 şi 18 ani, vârsta medie fiind de 7,01 $\pm 5,09$ ani. $37(54,4 \%)$ au fost băieți iar $31(45,6 \%)$ au fost fete.

Motivele de internare au fost hematochezia 37 $(54,4 \%)$, rectoragia $26(38,2 \%), 5(7,4 \%)$ pacienți au avut cel puțin două teste consecutive pozitive pentru hemoragii oculte. (Fig. 5)

Cea mai frecventă cauză a HDI constatată a fost polipul colo-rectal, 28 (41,2\%), colita ulcerativă 14 (20,6\%), leziuni nespecifice $12(17,6 \%)$ constând în: inflamație localizată sau diseminată, fisuri, leziuni eritematoase; fisuri anale $9(13,2 \%)$, polipoză intestinală 3 (4,4\%,1 caz de sindrom Peutz-Jeghers, 1 caz de sindrom Bannayan-Ryley, 1 caz de sindrom Gardner), diverticul rectal 1 (1,5\%) şi malformații vasculare $1 \mathrm{caz}(1,5 \%)$. (Fig. 6) Polipii colo-rectali au avut diametru între $0,5-1,5 \mathrm{~cm}$, marea majoritate au fost localizați pe recto-sigmoid şi toți polipii au fost extraşi în aceeaşi şedință de colonoscopie, iar

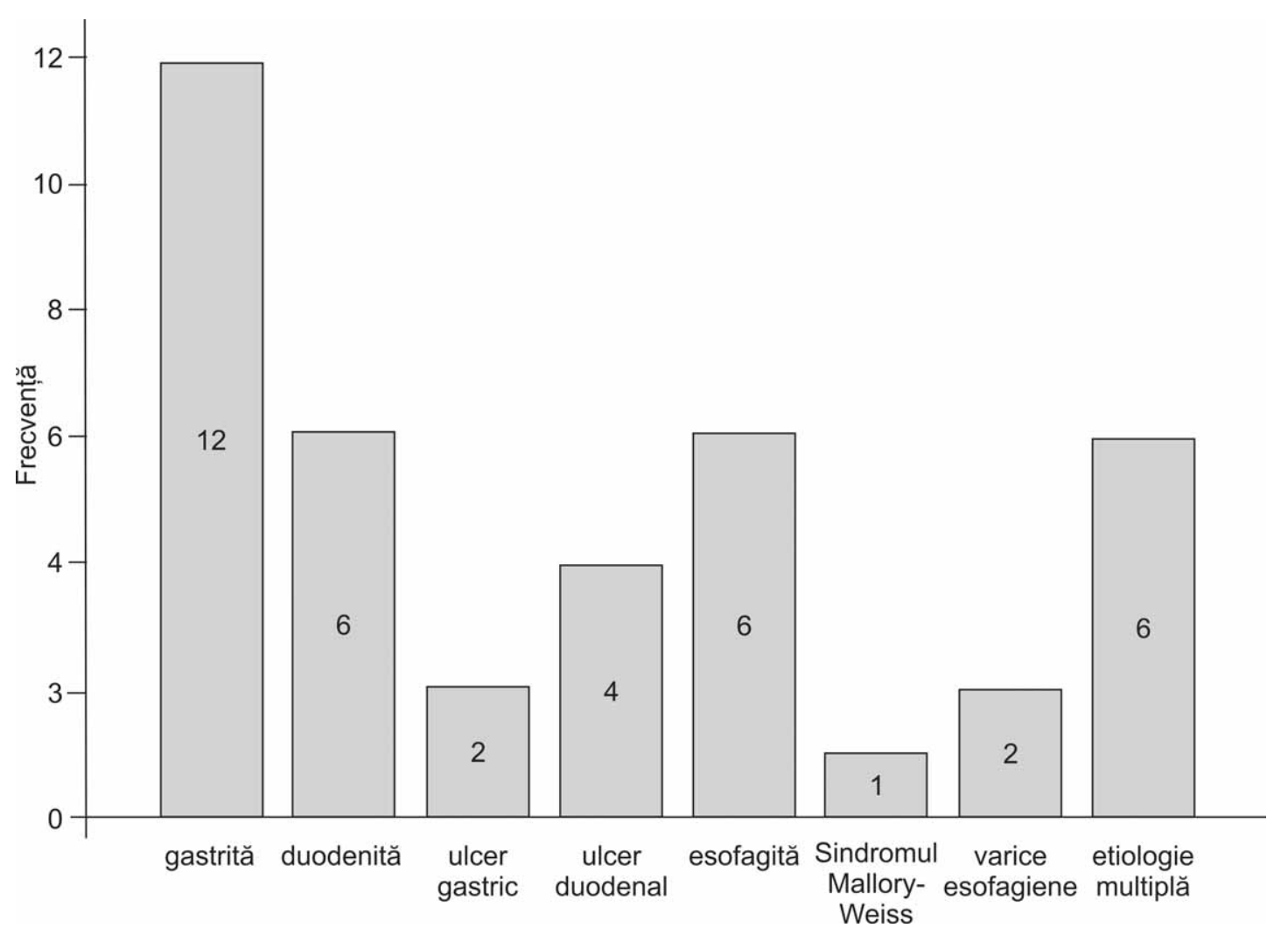

FIGURA 4. superioare 


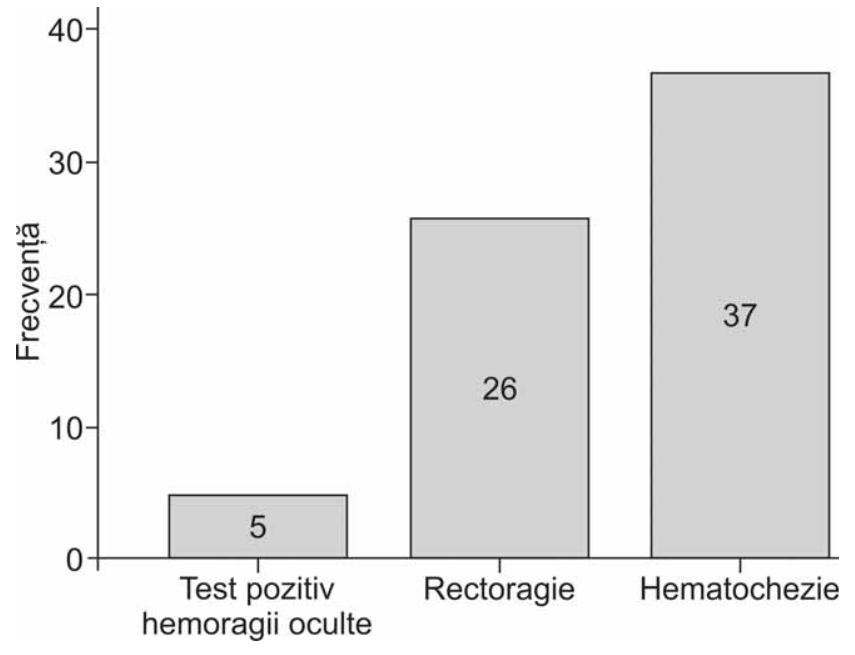

FIGURA 5. Motivele prezentării pe sublotul cu hemoragie digestivă inferioară

din punct de vedere histologic polipii au fost de tip juvenil. Departajarea cazurilor pe sexe a evidențiat că principalul factor etiologic a fost polipul colorectal 17 cazuri $(45,9 \%)$ la băieți şi 11 cazuri $(35,5 \%)$ la fete.

\section{DISCUȚII}

Hemoragia digestivă este un eveniment alarmant în rândul copiilor şi părinților și un motiv serios de adresare la spital. De cele mai multe ori sângerarea gastrointestinală este autolimitată şi nu alterează statusul hemodinamic, cu toate acestea adresabilitatea la serviciile medicale în vederea diagnosticului şi tratamentului este ridicată, fapt demonstrat şi prin acest studiu unde agentul etiologic frecvent al hemoragiilor digestive inferioare au fost fisurile anale. Studii anterioare au arătat că sângerarea rectală la copii este de cele mai multe ori o situație autolimitată, care nu necesită tratament, ci doar măsuri suportive. $(4,5)$

Atât în sublotul cu hemoragie digestivă superioară, cât şi în sublotul cu hemoragie digestivă inferioară, distribuţia pe sexe arată o predominanță a sexului masculin dar fără diferențe semnificative statistic $(\mathrm{p}<0,1)$, fapt demonstrat şi în alte studii. $(6,7)$ Această predominanță este atribuită de unii autori efectului protectiv al estrogenului asupra agresiunilor suferite de mucoasa gastrică şi duodenală, argument demonstrat şi de Smith şi colaboratorii. (8)

Hematemeza a fost cel mai important simptom de prezentare în cazul hemoragiilor digestive superioare reprezentând $46,2 \%$, urmată de melenă $35,9 \%$, rezultate apropiate prezentate şi în alte studii - 50\% El. Mouzan, 2004 şi 68,8\% Huang IF, 2003. O explicație ar putea fi dată de faptul că hematemeza este un eveniment alarmant pentru pacient şi familie comparativ cu melena care este observată mai târziu ducând la o prezentare tardivă la serviciile medicale. $(9,10)$

În cazul hemoragiei digestive inferioare hematochezia a fost cel mai frecvent simptom de prezentare, urmată de rectoragie date similare raportate în studii conduse de Hossein şi colaboratorii. (11)

Principala etiologie în cazul HDS a fost gastrita erozivă reprezentând $30,8 \%$ dintre pacienți, rezultate asemănătoare cu cele din studii elaborate de El

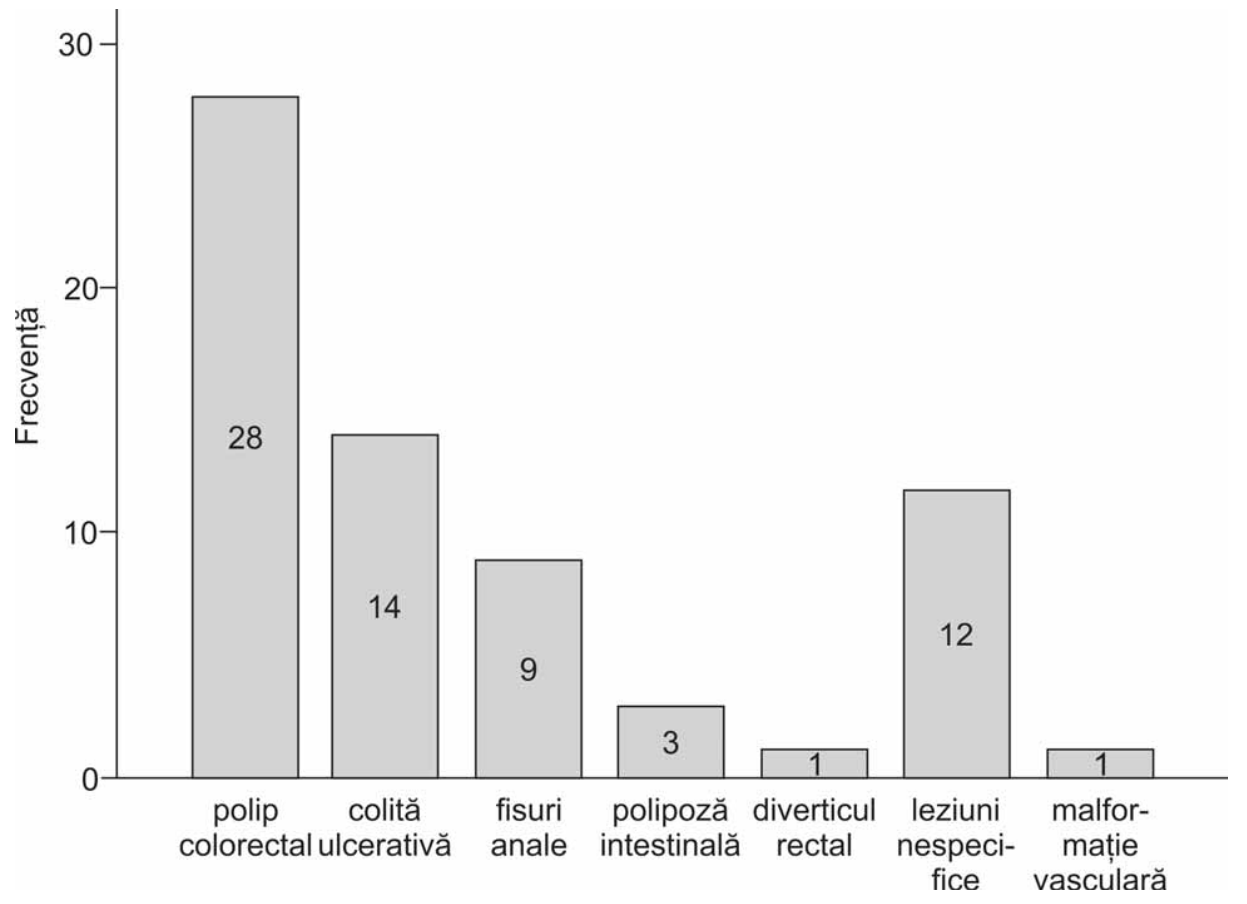

FIGURA 6. Etiologia hemoragiei digestive inferioare 
Mouzan (44,0\%) şi Huang IF $(44,6 \%) .(9,10)$ Sângerările variceale au reprezentat $5,1 \%$, un procent destul de mic, explicația putând fi faptul că această patologie este întâlnită mai des în centrele terțiare de hepatologie, unitatea noastră fiind mai curând un centru care asigură servicii de gastroenterologie. În țările dezvoltate, sângerarea variceală apare în procente mai ridicate, 39\% (Abdullah et al, 2012), şi 23,4\% (Quak SH, 1990). (12,13) A doua cauză a hemoragiei digestive superioare a fost esofagita erozivă $15,4 \%$, esofagita fiind în general secundară bolii de reflux gastro-esofagian, date asemănătoare au fost întâlnite şi înalte studii. (14)

Ulcerul gastric şi duodenal au avut o frecvență $5,3 \%$ şi respectiv $10,1 \%$, rezultate comparabile fiind raportate de El Mouzan 2004 (8,5\% vs 6,8\%) şi Mittal SK 1994 (1,3\% vs 0,4\%). $(9,15)$

Istoricul de consum de medicamente a fost înregistrat la opt bolnavi $(20,5 \%)$ şase au ingerat antiinflamatorii nesteroidiene pentru o perioadă scurtă de timp pentru afecțiuni respiratorii intercurente şi doi pacienți au ingerat steroizi pentru afecțiuni ca artrita cronică juvenilă, sindrom nefrotic, date comparabile cu cele găsite de Mittal şi El Mouzan. $(9,15)$

Corelația dintre infecția cu $H$. pylori şi sângerarea gastrointestinală superioară a fost sugerată de prezența acestei infecții gastrice la 51,3\% bolnavi. În România prevalența infecției cu $H$. pylori este de $36,65 \%$ (Slăvescu, 2012) incidența mai mare a infecției cu H. Pylori apare în țări cu o prevalență mai mare a ulcerului gastric. $(7,16)$

În ceea ce priveşte hemoragia digestivă inferioară, principala etiologie a fost polipul colo-rectal reprezentând 41,2\%, urmat de colita ulcerativă, leziuni nespecifice şi fisuri anale, rezultatele prezentate sunt apropiate cu alte studii similare. Cea mai comuna cauză de hemoragie digestivă inferioară în Orientul Mijlociu, țările vestice şi populația chineză este polipul colo-rectal. $(5,17,18) \mathrm{La}$ populația egipteană, principala cauză de hemoragie digestivă inferioară este colita infecțioasă, urmată de polipul colo-rectal. (19) Cea mai comună formă de polipi sunt polipii juvenili de obicei solitari, am avut doar 3 cazuri de polipoză intestinală unde am găsit polipi cu dimensiuni între 0,5 şi $2 \mathrm{~cm}$. Rezecția endoscopică a polipilor a fost efectuată în 28 de cazuri şi nu au existat complicații în timpul intervenţiei.

Fisurile anale reprezintă un important factor etiologic însumând 13,2\%, acestea apar de obicei secundar constipației cronice frecventă la preşcolari şi şcolari. Aceste aspecte ar trebui investigate prin studii viitoare pentru a elucida condițiile favorizante sau substratul acestei patologii.

Colita ulcerativă a reprezentat 20,6\%. Făcând o comparație cu alte studii efectuate în populația vestică (20), reprezintă un procent destul de important şi totodată un semnal de alarmă care necesită investigații ulterioare.

\section{CONCLUZII}

Hemoragia digestivă inferioară a fost cel mai frecvent corelată cu cauze minore: polipii colorectali, fisuri anale, leziuni nespecifice.

Hemoragia digestivă non-variceală forma cea mai frecventă s-a asociat cu gastrita erozivă, esofagita, duodenita, ulcerul gastric.

Endoscopia digestivă s-a dovedit a fi o investigație utilă în diagnosticul hemoragiilor digestive şi cu aport terapeutic în anumite cazuri.

Hemoragia digestivă trebuie investigată cu prudență prin endoscopie/colonoscopie, având în vedere variatele aspecte etiologice combinând şi rolul terapeutic pe care îl poate avea în anumite patologii.

Mulțumiri: Mulțumim întregului personal al Unităţii de Endoscopie şi Compartimentului de Anatomie Patologică; fără sprijinul lor acest studiu nu s-ar fi realizat. 